\title{
Levothyroxine liquid solution versus tablet form for replacement treatment in
}

pregnant women

Carlo Cappelli ${ }^{1}$, Roberto Negro ${ }^{2}$, llenia Pirola ${ }^{1}$, Elena Gandossi ${ }^{1}$, Barbara Agosti ${ }^{1}$, Maurizio Castellano'.

1. Department of Clinical and Experimental Sciences, Endocrine and Metabolic Unit, University of Brescia, c/o $2^{\wedge}$ Medicina Spedali Civili di Brescia, Piazzale Spedali Civili no. 1, 25100 Brescia, Italy.

2. Division of Endocrinology, "V. Fazzi” Hospital. Piazza F. Muratore. 73100, Lecce (Italy).

Short title: Levothyroxine in pregnant women

Keywords: Levothyroxine, liquid solution, hypothyroidism, pregnant women

word count: 1492

Corresponding author:

C. Cappelli, MD

Department of Clinical and Experimental Sciences, Endocrine and Metabolic Unit, University of Brescia.

c/o $2^{\wedge}$ Medicina Spedali Civili di Brescia

Piazzale Spedali Civili ${ }^{\circ} 1$

25100 Brescia (Italy)

tel. ++390303995251

e-mail: cappelli@med.unibs.it 


\section{ABSTRACT}

Objective: To evaluate the need and the magnitude of Levothyroxine (LT4) increase in hypothyroid pregnant women on liquid compared to tablet formulations.

Methods: Patients were recruited by searching our 'thyroid patients' database. The selection criteria were as follows: a) pregnant women on treatment for hypothyroidism (both liquid or tablet LT4) who have given birth at our hospital between February 2012 and January 2014; b) TSH and FT4 level obtained at least three months before missed menstrual cycle, with a TSH value less than $2.5 \mathrm{mlU} / \mathrm{L}$; c) TSH and FT4 obtained within 12 weeks of pregnancy, and each month subsequently.

Results: During pregnancy, $8 / 31(25.5 \%)$ of the women had to increase the dosage of LT4. Of these, $7 / 17$ (41.2\%) were on LT4 replacement therapy with tablet, and 1/14 (7.1\%) with liquid formulation ( $p=0.038$ ). Daily LT4 was significantly increased in liquid group only ( $52.9 \pm 19.5$ vs $67.5 \pm 19.2 \mathrm{mcg} /$ day $(p=0.013)$. A logistic regression analysis showed that treatment with LT4 tablet was the only predictor of LT4 increase (OR $0.44,95 \% \mathrm{Cl} 0.04$ $0.83 ; p=0.031)$.

Conclusion: Pregnant women on optimal replacement therapy before pregnancy, require increase of LT4 dose more often if on tablet than liquid formulation. 


\section{INTRODUCTION}

Hypothyroidism in pregnancy is defined as TSH above the trimester-specific reference range and is subdivided in subclinical or overt, depending on FT4 values within or below the normal range, respectively. Current Guidelines suggest to adopt local trimester specific range for $\mathrm{TSH}$, and in absence of this, to consider an upper limit of $2.5 \mathrm{mIU} / \mathrm{L}$ in the first, $3.0 \mathrm{mIU} / \mathrm{L}$ in the second and 3.0-3.5 mIULL in the third trimester [1-4]. The state of pregnancy requires an adaptation of thyroid function that results physiologically increased [5]. That is the reason why hypothyroid women on replacement treatment with Levothyroxine (LT4), usually require an increase of LT4 amount by $30-50 \%$ at the beginning of pregnancy [6]. The need and the magnitude of LT4 increase depend on the etiology of hypothyroidism and the pre-pregnancy TSH level $[7,8]$. Traditionally, LT4 is administered in form of tablet, but soft gel capsule or liquid formulations are available in some European Countries. Recent studies have shown a better absorption of soft gelliquid formulation than tablet, hesitating in more stable TSH values [9-11]. The aim of the study is to retrospectively evaluate the need and the magnitude of LT4 increase in hypothyroid pregnant women on liquid compared to tablet formulation. 


\section{SUBJECTS AND METHODS:}

Women were recruited by searching the database of patients treated and followed at the Thyroid Unit of the Department of Clinical and Experimental Science, University of Brescia. The search criteria were as follows: a) pregnant women on treatment for hypothyroidism (both liquid or tablet LT4) who have given birth at our hospital between February 2012 and January 2014; b) TSH and FT4 level obtained at least three months before missed menstrual cycle, with a TSH value less than 2.5 mIUIL; c) TSH and FT4 obtained within 12 weeks of pregnancy, and each month subsequently; d) detailed LT4 treatment; e) detailed other drugs therapy (if any). As per protocol adopted in our Institution, in case of TSH higher than the pregnancy specific reference range, LT4 was increased by $25 \mu \mathrm{g} / \mathrm{day}$ at each visit. All women satisfying the above criteria were enrolled in this study and informed consent was obtained from all subjects. The study was approved by the Institutional Review Board. Serum concentrations of free thyroxine (FT4 normal range 8.0-19 pglml, analytical sensitivity $1 \mathrm{pg} / \mathrm{ml}$; intra and inter-assay coefficient of variation, 2.4 and $6.8 \%$, respectively); TSH (normal range: 0.2-4.2 mIULL, analytical sensitivity $0.004 \mathrm{mIULL}$; intra and inter-assay coefficient of variation, 2.5 and $5.7 \%$, respectively) were measured by means of chemiluminescence immunoassay using an automated analyser (Immulite 2000, DPC Cirrus, Los Angeles, CA, USA), employing commercial kits (Diagnostic Products Corporation, Los Angeles, CA, USA). Blood thyroid stimulating hormone (b-TSH) on

neonatal Guthrie cards was measured by automated fluoro-immunoassay (Autodelfia technology; Perkin-Elfmer Life Science). The blood sample was collected between days 24 after birth in the newborn and the b-TSH cur-off values was $10 \mathrm{mIUIL}$. 


\section{Statistics}

Statistical analysis was performed using SPSS 17.0 software (SPSS, Imnc, Evanston, IL, USA). Mann-Whitney $U$ test was performed to evaluate TSH and FT4 distribution. Comparisons between groups and difference between proportions were calculated using ANOVA test for quantitative variables, as appropriate. A logistic analysis was performed to examine the influence of confounders on the hormonal thyroid profile. Two-tailed $p<0.05$ was considered significant. Data are presented as mean \pm standard deviation. 


\section{Results}

Between February 2012 and January 2014, 31 hypothyroid pregnant who satisfied the above mentioned criteria gave birth at our hospital. All the subjects were nulliparous, and suffered from Hashimoto's thyroiditis. Fourteen patients were in replacement therapy with liquid LT4 and 17 were on tablet. Baseline demographics and clinical characteristics are shown in Table I. No difference in age and body weight, were observed between patients on liquid and tablet treatment. All the patients assumed multivitamin pills containing iron and iodine. No difference was observed in thyroid function test before pregnancy between the tablet and the liquid group. Pre-pregnancy TSH and FT4 values were similarly distributed in the two groups. During pregnancy, $8 / 31$ (25.5\%) of the women had to increase the dosage of LT4. Of these, 3 women increased LT4 within 12 weeks, and 5 between 13-24 weeks. Among them, 7/17 (41.2\%) were on LT4 replacement therapy with tablet, and $1 / 14(7.1 \%)$ with liquid formulation $(p=0.038)$. The mean dose of LT4 from baseline to delivery was significantly increased only in women on tablet, as opposed to those on liquid therapy $(52.9 \pm 19.5$ vs $67.5 \pm 19.2 \mathrm{mcg} / \mathrm{day}(\mathrm{p}=0.013)$, and $53.6 \pm 25.7$ vs $55.4 \pm 29.7 \mathrm{mcg} /$ day $(\mathrm{p}=0.34)$, respectively.

There was no significant difference between women who needed to increase LT4 and those who did not (Table II). There was no significant difference in parameters of newborn from mothers who needed to increase LT4 and those who did not (Table III).

A logistic regression analysis taking into account age, pre-pregnancy and delivery weight, gestational weight gain, TSH values, showed that treatment with LT4 tablet was the only predictor of LT4 increase (OR $0.44,95 \% \mathrm{Cl} 0.04-0.83 ; \mathrm{p}=0.031)$. 


\section{Discussion}

Either American or European Guidelines about treatment of thyroid disease in pregnancy suggest to treat hypothyroid women in order to keep TSH within trimester specific reference range [1-4]. Increased TSH levels are associated with adverse events like miscarriage, gestational hypertension and preeclampsia, gestational diabetes, intrauterine growth restriction, neonatal low birth weight, reduced intelligence quotient in the offspring $[12,13]$. Given the well known variation in demand of thyroid hormones during pregnancy, a prospective study demonstrated that in hypothyroid women, an increase of two tablet per week is able to maintain TSH within the pregnancy reference range, then mimicking the physiological adaptation of an healthy thyroid to the pregnant state [14]; the need for an increase of LT4 dosage may be even higher than $30 \%$ in hypothyroidism induced by radioiodine or total thyroidectomy; other than the etiology of hypothyroidism, also the prepregnancy TSH level should be taken into account when deciding the variation dose: data suggest that increased LT4 dosage is necessary in $50 \%$ of cases when pre pregnancy TSH is 1.2-2.4 mIUIL versus $17 \%$ when TSH is lower than 1.2 mIUIL $[7,15,16]$.

In the present study that evaluated LT4 treatment in hypothyroid patients on liquid or tablet formulation we observed that, despite similar pre-pregnancy TSH levels (mean and distribution) the liquid-treated group require to increase the LT4 dose in a minority of cases. A possible explanation for this result may rely on the different characteristic of absorption demonstrated by the two formulations. Indeed, the gastric $\mathrm{pH}$ is one of the most important factors that influence the absorption of LT4, in an inversely proportional manner: the absorption capacity decreases with the increase of $\mathrm{pH}[17,18]$. Centanni et al. have demonstrated that patients with impaired acid secretion require an increase dose of thyroxine, confirming that normal acid gastric secretion is necessary for effective absorption of oral LT4 [19]. It is well known that during pregnancy gastric emptying and 
small intestine motility are reduced by $30-50 \%$ due to elevation of progesterone (20-22). In addition, these changes alter bioavailability parameters like maximum concentration (Cmax) and time to maximum concentration (Tmax) of orally administered medication. The decrease in Cmax and increase in Tmax particularly affect medication taken daily as a single dose [23]. Another relevant modification during pregnancy is represented by an increase in gastric $\mathrm{pH}$, due to a reduction of $\mathrm{H}^{+}$secretion and an increase in mucus production, which may increase the ionization of weak acids, tending to reduce their absorption more than that of weak bases [20, 21]. Many recent reports have clearly demonstrated that liquid LT4 formulation circumvents these problems, in patients taking proton pump inhibitors, those suffering from gastric related T4 malabsorption, those assuming T4 with coffee or fed by enteral tube, and also those submitted to bariatric surgery [24-28]. As our pregnant patients on tablet required to increase LT4 more often than those on liquid, it is possible that the usual increase in exogenous LT4 requirement may be partly due to altered LT4 tablet absorption and not exclusively to pregnancyrelated thyroid hormone increased demand. A major concern is represented by the alcohol content $(243 \mathrm{mg})$ that is present in vials of liquid formulation. As a matter of fact, current guidelines recommend abstinence from alcohol for women planning pregnancy, at conception, and during pregnancy $[29,30]$. A recent meta-analysis did not find a significant increase in risk of low birth weight and small for gestational age for alcohol daily intake lower than $10 \mathrm{~g}$, and risk of preterm birth for a daily intake lower than $18 \mathrm{~g}$ [31]. Our study as well did not find any difference between in characteristics of newborn from mother on liquid and tablet formulation.

In conclusion, although limited by the retrospective collection of data, and the small number of patients, results show that hypothyroid pregnant women on optimal replacement therapy before pregnancy, require increase of LT4 dose more often if on tablet than liquid formulation. Randomized prospective studies are necessary to confirm 
this preliminary finding, that may have relevant clinical implications in the treatment of hypothyroidsm in pregnancy. 


\section{Declaration of interest:}

C. Cappelli, R. Negro, I. Pirola, E. Gandossi, B. Agosti and M. Castellano have no conflicts of interest to declare.

\section{Author contributions:}

C. Cappelli, R. Negro and I. Pirola designed the purpose of this study. E. Gandossi and B. Agosti did the literature search and selection, and wrote the manuscript. C. Cappelli, R. Negro, I. Pirola, E. Gandossi, A. B. Agosti and M. Castellano collaborated equally in the literature search and selection, and in the paper revision. 


\section{References:}

[1] Garber JR, Cobin RH, Gharib H, Hennessey JV, Klein I, Mechanick JI, Pessah-Pollack R, Singer PA, Woeber KA; American Association of Clinical Endocrinologists and American Thyroid Association Taskforce on Hypothyroidism in Adults. Clinical practice guidelines for hypothyroidism in adults: cosponsored by the American Association of Clinical Endocrinologists and the American Thyroid Association. Endocrine Practice 2012; 18: 988-1028.

[2] Stagnaro-Green A, Abalovich M, Alexander E, Azizi F, Mestman J, Negro R, Nixon A, Pearce EN, Soldin OP, Sullivan S, Wiersinga W; American Thyroid Association Taskforce on Thyroid Disease During Pregnancy and Postpartum. Guidelines of the American Thyroid Association for the diagnosis and management of thyroid disease during pregnancy and postpartum. Thyroid $2011 ; 21: 1081-1125$.

[3] De Groot L, Abalovich M, Alexander EK, Amino N, Barbour L, Cobin RH, Eastman CJ, Lazarus JH, Luton D, Mandel SJ, Mestman J, Rovet J, Sullivan S. Management of thyroid dysfunction during pregnancy and postpartum: an Endocrine Society clinical practice guideline. The Journal of Clinical Endocrinology \& Metabolism 2012; 97: 2543-2565

[4] Lazarus J, Brown RS, Daumerie C, Hubalewska-Dydejczyk A, Negro R, Vaidya B. 2014 European thyroid association guidelines for the management of subclinical hypothyroidismin pregnancy and in children. European Thyroid Journal 2014; 3:76-94.

[5] Glinoer D. What happens to the normal thyroid during pregnancy? Thyroid 1999; 9: 631-635.

[6] Alexander EK. Marqusee E. Lawrence J. Jarolim P. Fischer GA, Larsen PR. Timing and magnitude of increases in levothyroxine requirements during pregnancy in women with hypothyroidism. New England Journal of Medicine 2004; 351: 241-249. 
[7] Abalovich M, Alcaraz G, Kleiman-Rubinsztein J, Pavlove MM, Cornelio C, Levalle O, Gutierrez S. The relationship of preconception thyrotropin levels to requirements for increasing the levothyroxine dose during pregnancy in women with primary hypothyroidism. Thyroid 2010; 20: 1175-1178.

[8] Verga U, Bergamaschi S, Cortelazzi D, Ronzoni S, Marconi AM, Beck-Peccoz P. Adjustment of L-T4 substitutive therapy in pregnant women with subclinical, overt or post-ablative hypothyroidism. Clinical Endocrinology 2009; 70: 798-802.

[9] Vita R, Fallahi P, Antonelli A, Benvenga S. The administration of L-thyroxine as soft gel capsule or liquid solution. Expert Opinion on Drug Delivery 2014; 11: 1103-1111.

[10] Negro R, Valcavi R, Agrimi D, Toulis KA. Levothyroxine liquid solution versus tablet for replacement treatment in hypothyroid patients. Endocrine Practice 2014; 20: 901-906.

[11] C. Cappelli, I. Pirola, L. Daffini, B. Agosti, M. Castellano. Thyroid hormonal profile in elderly patients treated with two different levothyroxine formulations: A single institute survey. European Geriatric Medicine 2014; 5: 382-385.

[12] Negro R, Stagnaro-Green A. Diagnosis and management of subclinical hypothyroidism in pregnancy. British Medical Journal 2014; 349: 4929.

[13] Stagnaro-Green A. Overt hyperthyroidism and hypothyroidism during pregnancy. Clinical Obstetrics and Gynecology 2011; 54: 478-487. 
[14] Yassa L, Marqusee E, Fawcett R, Alexander EK. Thyroid hormone early adjustment in pregnancy (the THERAPY) trial. The Journal of Clinical Endocrinology \& Metabolism 2010; 95: 3234-3241.

[15] Mandel SJ. Larsen PR. Seely EW, Brent GA. Increased need for thyroxine during pregnancy in women with primary hypothyroidism. New England Journal of Medicine 1990; 323: 91-96.

[16] Kothari A, Girling J. Hypothyroidism in pregnancy: pre-pregnancy thyroid status influences gestational thyroxine requirements. BJOG 2008; 115: 1704-1708.

[17] laniro G, Mangiola F, Di Rienzo TA, Bibbò S, Franceschi F, Greco AV, Gasbarrini A. Levothyroxine absorption in health and disease, and new therapeutic perspectives. European Review for Medical and Pharmacological Sciences 2014; 18: 451-456.

[18] Sachmechi I, Reich DM, Aninyei M, Wibowo F, Gupta G, Kim PJ. Effect of proton pump inhibitors on serum thyroid-stimulating hormone level in euthyroid patients treated with levothyroxine for hypothyroidism. Endocrine Practice 2007; 13: 345-349.

[19] Centanni M, Gargano L, Canettieri G, Viceconti N, Franchi A, Delle Fave G, Annibale B Thyroxine in goiter, Helicobacter pylori infection, and chronic gastritis. New England Journal of Medicine 2006; 354: 1787-1795.

[20] Costantine MM. Physiologic and pharmacokinetic changes in pregnancy. Frontiers in Pharmacology 2014; 5: 1-5.

[21] Dawes M, Chowienczyk PJ. Drugs in pregnancy. Pharmacokinetics in pregnancy. Best Practice \& Research Clinical Obstetrics \& Gynaecology 2001; 15: 819-826. 
[22] Cappell M, Garcia, A. Gastric and duodenal ulcers during pregnancy. Gastroenterology Clinics of North America 1998; 27: 169-195.

[23] Parry E, Shields R, Turnbull A.C. Transit time in the small intestine in pregnancy. Journal of Obstetrics \& Gynaecology of the British Commonwealth 1970; 77: 900-901.

[24] Vita R, Saraceno G, Trimarchi F, Benvenga S. Switching levothyroxine from the tablet to the oral solution formulation corrects the impaired absorption of levothyroxine induced by proton-pump inhibitors. The Journal of Clinical Endocrinology \& Metabolism 2014; 99: 4481-4486.

[25] Santaguida MG, Virili C, Duca SC, Cellini M, Gatto I, Brusca N, De Vito C, Gargano L, Centanni M. Thyroxine softgel capsule in patients with gastric-related T4 malabsorption. Endocrine 2015; 49: 51-57.

[26] Cappelli C, Pirola I, Gandossi E, Formenti A, Castellano M. Oral liquid levothyroxine treatment at breakfast: a mistake? European Journal of Endocrinology 2013; 170: 95-99.

[27] Pirola I, Daffini L, Gandossi E, Lombardi D, Formenti A, Castellano M, Cappelli C. Comparison between liquid and tablet levothyroxine formulations in patients treated through enteral feeding tube. Journal of Endocrinolology Investigation 2014; 37: 583-587.

[28] Pirola I, Formenti AM, Gandossi E, Mittempergher F, Casella C, Agosti B, Cappelli C. Oral liquid L-thyroxine (L-t4) may be better absorbed compared to L-T4 tablets following bariatric surgery. Obesity Surgery 2013; 23: 1493-1496.

[29] Shawe J, Delbaere I, Ekstrand M, Hegaard HK, Larsson M, Mastroiacovo P, Stern J, Steegers E, Stephenson J, Tydén T. Preconception care policy, guidelines, recommendations and services across six European countries: Belgium (Flanders), Denmark, Italy, the Netherlands, Sweden and 
the United Kingdom. The European Journal of Contraception and Reproductive Health Care 2015; 20: 77-87.

[30] Procter SB, Campbell CG. Position of the Academy of Nutrition and Dietetics: nutrition and lifestyle for a healthy pregnancy outcome. Journal of the Academy of Nutrition and Dietetics 2014; 114: 1099-1103.

[31] Patra J, Bakker R, Irving H, Jaddoe VW, Malini S, Rehm J. Dose-response relationship between alcohol consumption before and during pregnancy and the risks of low birthweight, preterm birth and small for gestational age (SGA)-a systematic review and meta-analyses. BJOG 2011; 118: 1411-1421. 
Table I. Baseline demographics and clinical characteristics of women before pregnancy

\begin{tabular}{|l|c|c|c|}
\hline & $\begin{array}{c}\text { Hypothyroid women on } \\
\text { liquid LT4 (14 patients) }\end{array}$ & $\begin{array}{c}\text { Hypothyroid women on } \\
\text { tablet LT4 (17 patients) }\end{array}$ & p value \\
\hline Age (yrs) & $28 \pm 3.8$ & $27.3 \pm 3.5$ & 0.599 \\
\hline Weight $(\mathbf{k g})$ & $59.5 \pm 2.8$ & $58.8 \pm 4.2$ & 0.609 \\
\hline LT4 dosage $(\mathbf{m c g})$ & $53.6 \pm 25.7$ & $52.9 \pm 19.5$ & 0.939 \\
\hline TSH $(\mathbf{m U l} / \mathbf{L})$ & $1.6 \pm 0.8$ & $1.4 \pm 0.8$ & 0.592 \\
\hline fT4 $(\mathbf{p g} / \mathbf{m L})$ & $10.9 \pm 1.4$ & $10.3 \pm 1.3$ & 0.308 \\
\hline
\end{tabular}


Table II. Age and body weight of women who needed to increase LT4 and those who did not.

\begin{tabular}{|l|c|c|c|}
\hline & $\begin{array}{c}\text { Women who needed to } \\
\text { increase LT4 dosage (8 } \\
\text { patients) }\end{array}$ & $\begin{array}{c}\text { Women with no need to } \\
\text { increase LT4 dosage (23 } \\
\text { patients) }\end{array}$ & $\begin{array}{c}\mathbf{p} \\
\text { value }\end{array}$ \\
\hline Age (yrs) & $26.1 \pm 3.1$ & $28.1 \pm 3.7$ & 0.183 \\
\hline Weight pre-pregnancy $\mathbf{( k g )}$ & $57.8 \pm 3.9$ & $59.6 \pm 3.4$ & 0.212 \\
\hline Weight at delivery (kg) & $69.9 \pm 4.2$ & $71.1 \pm 3.7$ & 0.433 \\
\hline $\begin{array}{l}\text { Increase of weight during } \\
\text { pregnancy (\%) }\end{array}$ & $21.1 \pm 2.2$ & $19.4 \pm 2.5$ & 0.102 \\
\hline
\end{tabular}


Table III. Clinical parameters of newborn from mothers who needed to increase LT4 and those who did not.

\begin{tabular}{|l|c|c|c|}
\hline & $\begin{array}{c}\text { Newborn from mother who } \\
\text { has increased the LT4 } \\
\text { dosage (8 neonates) }\end{array}$ & $\begin{array}{c}\text { Newborn from mother who } \\
\text { has not increased the LT4 } \\
\text { dosage (23 neonates) }\end{array}$ & $\begin{array}{c}\mathbf{p} \\
\text { value }\end{array}$ \\
\hline Male/Female & $2 / 6$ & $8 / 15$ & 0.483 \\
\hline Gestational age (weeks) & $40.1 \pm 0.8$ & $39.3 \pm 0.9$ & 0.055 \\
\hline Head circumference (cm) & $35.2 \pm 1.1$ & $35.4 \pm 1.8$ & 0.771 \\
\hline Weight (g) & $3631 \pm 0.36$ & $3.683 \pm 0.29$ & 0.687 \\
\hline Length (cm) & $50.6 \pm 3.3$ & $51.1 \pm 2.8$ & 0.681 \\
\hline Apgar score 1 $\mathbf{1}^{\text {st }}$ minute & $8.4 \pm 1.3$ & $8.3 \pm 1.2$ & 0.844 \\
\hline b-TSH (mU/L) & $6.8 \pm 2.1$ & $6.8 \pm 1.3$ & 0.969 \\
\hline
\end{tabular}

